\title{
Effects of epizootic shell disease in American lobster Homarus americanus determined using a quantitative disease index
}

\author{
Bradley G. Stevens* \\ School of Marine Science and Technology, University of Massachusetts Dartmouth, 706 S. Rodney French Blvd., \\ New Bedford, Massachusetts 02744, USA
}

Present address: Living Marine Resources Cooperative Science Center, Carver Hall, University of Maryland Eastern Shore, Princess Anne, Maryland 21853, USA

\begin{abstract}
The incidence of epizootic shell disease in American lobster Homarus americanus has increased in southern New England, USA, in the last decade, but few longitudinal studies have followed the disease progress in individual lobsters or demonstrated direct effects on mortality or growth. Diseased lobsters were held in the laboratory for $1 \mathrm{yr}$, and the progression of disease and its effects on molting, mortality, and growth were monitored. A quantitative disease index (QDI) was developed by measuring disease lesions in digital images of the carapace and expressing the result as a proportion of shell area. Some lobsters died due to high temperatures, but at least 13 of 55 lobsters $(24 \%)$ died as a direct result of disease-related problems, mostly during molting, and there was a significant relationship between mortality and high values of the QDI. Lobsters that molted successfully were free of disease lesions, but many had exoskeletal deformities. There was no relationship between pre-molt size and disease severity, but molt increment was significantly correlated with premolt carapace length (CL) and negatively correlated with QDI. However, percentage growth was negatively correlated with QDI, but not with pre-molt CL. These significant lethal and sublethal effects of epizootic shell disease should be considered in lobster management.
\end{abstract}

KEY WORDS: Lobsters · Homarus americanus $\cdot$ Disease $\cdot$ Molting $\cdot$ Growth

\section{INTRODUCTION}

Shell disease is a common term for a variety of symptoms exhibited by crustaceans, usually involving discoloration or disintegration of the shell (Sindermann 1989). Epizootic shell disease (ESD) in American lobsters Homarus americanus is defined by a particular set of symptoms including a progressively severe erosion of the carapace. The disease is associated with infestations of bacteria of the Flavobacteriaceae complex (Smolowitz et al. 2005a,b), recently suggested to be a novel species of the genus Aquimarina (A. Chistoserdov pers. comm., March 2009). Pathogenesis appears to be strictly dermal and does not affect internal organs. Bacterial diversity is similar on both healthy and diseased lobsters (Sullivan \& Nelson
2005). Diseased lobsters have bacterial loads that are from 2 to 4 orders of magnitude higher than healthy lobsters (Chistoserdov et al. 2005a), but apparently healthy lobsters in the early stages of disease may carry high densities of bacteria (Chistoserdov et al. 2005b). Protozoans are also abundant in disease lesions and may be part of a community succession (Sullivan \& Nelson 2005). Furthermore, bacteria found in lesions may inhibit growth of some types of amoebae (O'Kelly 2005). ESD is not highly contagious, and transmission among communally held lobsters has not been demonstrated (Cobb \& Castro 2006).

Diseased lobsters differ from healthy lobsters in several ways. Diseased lobsters spend significantly more time in shelters (Castro et al. 2005), but longer term movements of tagged lobsters in the ocean did not dif- 
fer whether they were diseased or healthy (Howell 2005). Prince \& Bayer (2005) studied lobster pound disease, which has a different appearance from ESD and may or may not be related. In their study, significantly lower initial levels of hemolymph serum protein, glucose, and phosphorus were found among lobsters that later developed impoundment disease. Diseased lobsters also had decreased muscle carbohydrate, altered protein profiles, and different fatty acid profiles than healthy lobsters (Prince \& Bayer 2005). All of these symptoms are indicative of increased stress levels in lobsters, whether associated with impoundment disease or ESD. Diseased lobsters were found to have higher levels of ecdysone than normal lobsters, especially among ovigerous females, and higher levels of blood contamination with alkylphenols (Laufer et al. 2005). Alkylphenols are anthropogenic pollutants found in many marine sediments and are endocrine disruptors with juvenile hormone-like activity. These contaminants may interfere with the formation of the exoskeleton, and such irregularities may lead to differences in susceptibility to ESD (Tarsitano \& Lavalli 2005). However, there is no indication that sediment concentrations of alkylphenols have increased since 1997. Furthermore, lobsters in the most polluted areas have the lowest incidence of ESD, and those with the highest incidence are found in the least polluted areas (McKown et al. 2005). Decreased shell hardness is also associated with ESD (Tlusty et al. 2007, Theriault et al. 2008).

The incidence of diseased lobsters increased dramatically in New England waters after 1996 (Castro \& Angell 2000), peaking at 30\% in 2002 in Rhode Island waters (Gibson \& Wahle 2005) and reaching a level of $43 \%$ in 2003 along the south shore of Long Island, New York (McKown et al. 2005). Increasing mortality of lobsters since that time has caused a change in the stockrecruitment $(\mathrm{S}-\mathrm{R})$ relationship between settling postlarvae and subsequent pre-recruit size lobsters, but a significant $\mathrm{S}-\mathrm{R}$ relationship can be produced by inclusion of a component function for shell disease (Gibson \& Wahle 2005). The incidence of ESD is highest before the molt in May, decreases occur in July following molting, and then increases occur again in the fall. Ovigerous females are 7.5 times more likely to exhibit ESD than non-ovigerous females, possibly due to their longer intermolt periods (Glenn \& Pugh 2006); smaller animals molt more frequently, so they show lower severity. ESD incidence appears to increase in postmolt months as the water temperature increases and has reached $57 \%$ in some parts of Buzzards Bay, MA. Discard-related injuries may provide a route for bacterial invasion (Glenn \& Pugh 2006). Initial symptoms of ESD occur on areas of the carapace that are difficult for the lobster to clean; however, there is no evidence yet that diseased lobsters show decreased grooming behavior.

The highest occurrence of ESD is in Buzzards Bay and corresponds with the higher mean temperatures there than in other parts of New England (Glenn \& Pugh 2006). This area is at the southern extent of the geographic range of American lobsters, where they may be under the greatest physiological stress. However, incidence of ESD has expanded northward steadily since 1977. In Boothbay Harbor, Maine, annual bottom water temperatures have increased by $2.5^{\circ} \mathrm{C}$ over the last $15 \mathrm{yr}$ (Wilson 2005). Increasing seawater temperature may exacerbate disease rates by accelerating bacterial growth or by reducing the ability of lobsters to clean their carapaces. In Massachusetts, the increasing occurrence of ESD is associated with increasing water temperature $\left(>20^{\circ} \mathrm{C}\right)$ (Glenn \& Pugh 2006), with a 1 yr lag period. This suggests that summer temperatures exacerbate the disease in postmolt lobsters that accumulate symptoms during the following intermolt period (Glenn \& Pugh 2006).

Most studies of ESD have focused on the pathology or local incidence of the disease, and have been conducted by sampling lobsters from wild populations or by averaging observations on captive animals. Both of these methods tend to obscure temporal and spatial trends because of the inherent variability in lobster biology, size, reproductive condition, molt timing, and susceptibility. Few longitudinal studies have followed disease progress in individual animals, except that of Tlusty et al. (2008), who studied the effects of diet on 1 to 2 yr old juveniles. Furthermore, the crude ESD index being used by field biologists does not have sufficient resolution to detect subtle differences in individual lobsters. The present study was undertaken to (1) develop a quantitative index of shell disease that can be used as a response variable for statistical comparisons; (2) determine the progress of shell disease symptoms in individual captive lobsters; and (3) determine the effect of shell disease on mortality, molting, and growth.

\section{MATERIALS AND METHODS}

Lobsters Homarus americanus were captured during surveys in October and November 2007 using strings of 3 standard commercial lobster traps (with escape vents), alternating with 3 ventless traps. All lobsters were captured at sites within Buzzards Bay, MA, USA. Lobsters with a wide range of symptoms of ESD were selected for the study. Ten lobsters were collected in this manner by graduate students from the School for Marine Science and Technology (SMAST) in October 2007, and an additional 45 lobsters were collected 
by the Massachusetts Division of Marine Fisheries (MDMF) in November 2007. Lobsters were returned to the seawater laboratory at SMAST, where they were placed into individual perforated baskets within 1 of 2 shallow tanks with flow-through, ambient temperature seawater. Seawater temperatures were recorded at hourly intervals with a small electronic data logger. Lobsters were fed twice weekly with a diet of squid Ilex sp. or herring Clupea harengus at a ratio of about 5:1.

Lobsters were removed from their baskets monthly and examined visually for the extent of ESD, after rinsing with ambient seawater to remove accumulated sediment. Biologists at the MDMF use a standardized shell disease index (SDI) with 4 categories (Glenn \& Pugh 2006): absent, no evidence of shell disease (Cat. 0); light, $<10 \%$ coverage (Cat. 1); moderate, from 10 to $50 \%$ coverage (Cat. 2); and severe, $>50 \%$ coverage (Cat. 3). A problem with this index is that a single number must be used to classify disease effects over the entire surface of the animal. While this does allow coding to be done rapidly at sea, it does not allow quantitative data analysis with any resolution and does not provide information on body regions affected. Therefore, a regional disease index (RDI) was developed by assigning the same 4 categories of disease symptoms to each of the 3 major body regions in the following order: abdomen, carapace, and chelae. When averaged, this index can take on 10 different values from 0 to 3 in 0.33 increments, allowing for finer resolution of the disease coverage. As a test case, 3 observers scored 17 lobsters each for both SDI and RDI, and the results were compared by regression. It was not possible to designate any lobsters as 'sterile' controls, because the pathogens causing ESD are present on most lobsters, and the disease cannot be detected easily in its early stages; however, 13 of the experimental lobsters had no visible disease symptoms (SDI Cat. 0).

After visually examining each lobster, it was placed on a vinyl measuring grid with an attached ruler and photographed from each side at a constant distance and angle of $45^{\circ}$ from the vertical using an 8-Mp digital camera with floodlights and diffused flash. Digital photographs were analyzed using Image-Pro Plus, v.4.5, after calibrating with the ruler in the photograph. Contrast or brightness was adjusted if necessary, and photographs were sharpened once. All exoskeletal disease lesions appearing in the photograph were outlined as polygons using an electronic drawing tablet and pen, and the resultant tracing was saved as an electronic file. Only the dorso-lateral portions of the abdomen, carapace, and chelae were included; other appendages and the ventral sides were not traced. The tracing file was then calibrated using the same value as the photograph; the areas of all polygons were measured automatically and exported to an Excel file.
The total surface area (SA) for each lobster was calculated using a modified regression equation based on carapace length $(\mathrm{CL}$, in $\mathrm{cm}$ ) derived from Kapareiko et al. (2003):

$$
\mathrm{SA}=12.6889 \times \mathrm{CL}^{1.9677} \times[0.679-(\mathrm{MC} \times 0.16)]
$$

where 0.679 represents the proportion of total SA examined (excluding small appendages and the ventral side), and $\mathrm{MC}$ is the number of missing chelae (which collectively account for $32 \%$ of the total SA). Partially regenerated chelae were given a count (MC) of 0.5. A quantitative disease index (QDI) was then calculated by summing all measured polygon areas (PA) for both sides of the lobster and dividing by the calculated SA of the lobster:

$$
\mathrm{QDI}=\Sigma \mathrm{PA} / \mathrm{SA}
$$

Two-dimensional photographs do not reflect the actual surface area of a curved body, which could cause differences between the estimated surface area and the area actually measured. For this reason a second method was also tested that used a tracing of the 2-dimensional lobster outline in each photograph as the reference surface area, instead of the calculated area. Linear regression of drawn versus calculated areas for 45 lobsters showed that these were highly correlated, with $\mathrm{R}^{2}=0.970$. Therefore, because obtaining the calculated area was much more efficient, that method was used for all subsequent data analysis.

Because lobsters exhibited a wide range of RDI values within any month (from 0 to 3 ), the mean values calculated across all lobsters had large variance and temporal changes were not detectable. Therefore, in order to analyze temporal change, the RDI and QDI values for each lobster were compared to the previous month's values, and the difference between them (RDiff or QDiff, respectively) was calculated. Any lobster with QDiff > 0.01 was re-examined to determine if the difference was valid (due to changes in symptoms) or due to other causes such as molting or measurement error. After reconciling such differences, most measurement errors amounted to $<0.005$. Mean QDiff was used as the test datum within each month.

QDI index values that were recorded in November 2007 (i.e. within $6 \mathrm{wk}$ of capture for all lobsters) were regressed on CL to determine if there was a relationship between CL and disease severity. After lobsters molted, they were allowed to harden for several weeks before CL was re-measured. Molt increment (MI) was calculated as the difference between pre- and postmolt measurements, and proportional growth (PG) was determined by expressing the molt increment as a proportion of pre-molt CL. The effect of QDI (measured in the month before molting) on both MI and PG was analyzed using multiple regression with size as a covari- 
ate. Multiple regression was also used to analyze the effects of disease severity (QDI) and CL on molting date, expressed as the number of days after 15 October 2007, using a backwards stepwise regression with $p$ to remove set at 0.15 . To determine the effect of shell disease on mortality, the maximum QDI value recorded for each lobster during the study was classified as being below or above a value of 0.16 , and a chisquared analysis was conducted on mortality, coded as 0 (survived) or 1 (died).

\section{RESULTS}

\section{Disease indices and severity}

Disease severity ranged from none $(\mathrm{SDI}=0)$ to severe (SDI = 3) (Fig. 1), and numbers of lobsters Homarus americanus in the standard categories were initially Cat. $0, \mathrm{n}=13$; Cat. $1, \mathrm{n}=23$; Cat. 2, $\mathrm{n}=18$; and Cat. $3, \mathrm{n}=10$. Some lobsters had lesions that com-
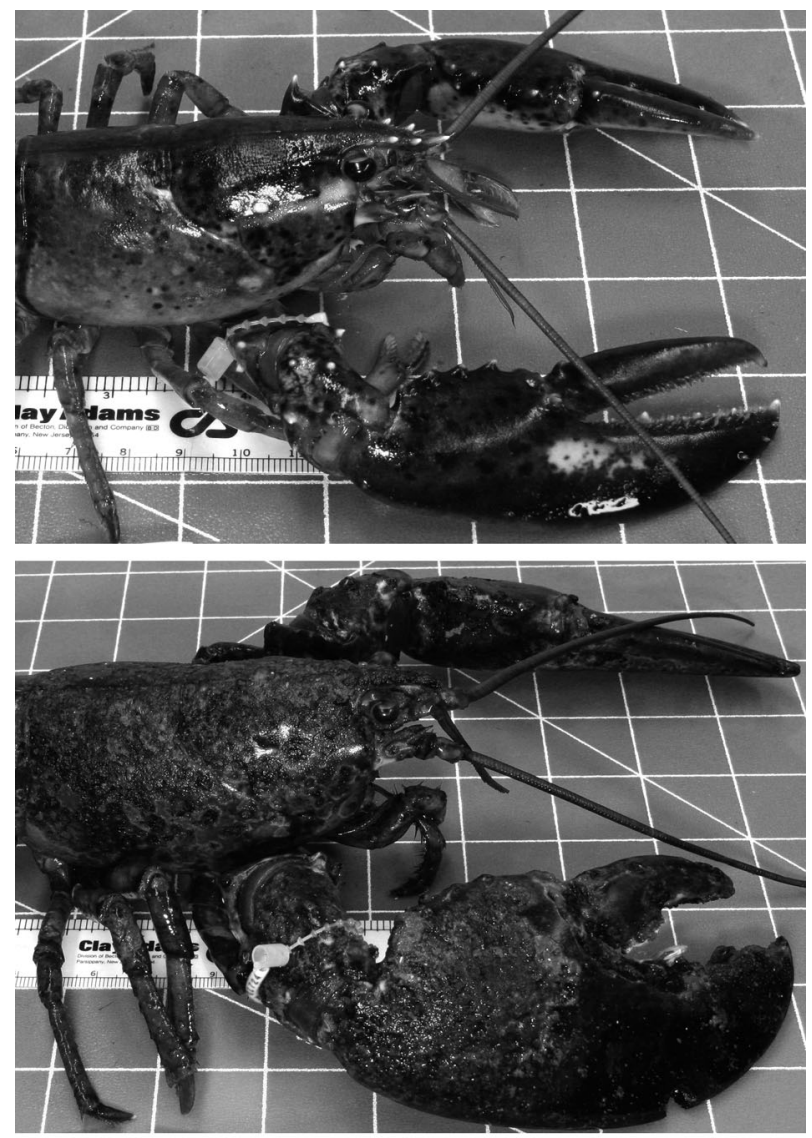

Fig 1. Homarus americanus. Lobsters with different degrees of epizootic shell disease in December 2007: (A) Lobster 1720, $\mathrm{SDI}=0$, $\mathrm{QDI}=0.00$; (B) Lobster 1724, $\mathrm{SDI}=3$, $\mathrm{QDI}=0.364$. SDI: shell disease index; QDI: quantitative disease index pletely penetrated the carapace or abdomen. The SDI and RDI indices of the test case were highly correlated $\left(\mathrm{r}^{2}=0.839\right)$, indicating that both provide useful information about disease coverage. However, visual observations using the RDI tended to clump together toward the higher values (Fig. 2). This is probably because the range of disease coverage was not equal among the categories used, e.g. Cat. 1 refers to only from 0 to $10 \%$ coverage, whereas Cat. 2 refers to a range from 10 to $50 \%$ coverage. In contrast, the QDI gave more precise estimates of disease coverage, with maximum values ranging from 0.0 to 0.38 ; most values were $<0.1$. The most severely diseased lobsters had QDI values $<0.40$ because, even though they were almost completely covered with disease lesions, only the dorso-lateral surface was visible in the digital photographs.

\section{Mortality}

A total of 55 lobsters were used in the study. Over a 12 mo period (through November 2008), 30 lobsters died $(54.5 \%)$, leaving 25 alive (Table 1$)$. Nine (16.4\%) died during a period of high water temperatures $\left(>20^{\circ} \mathrm{C}\right)$ in July 2007; at least two of those died when a contractor released foul water into the seawater system. Thirteen mortalities (23.6\%) could be attributed directly to shell disease; one of those died due to complications involving an open lesion, one after molting, and others due to complications during or immediately
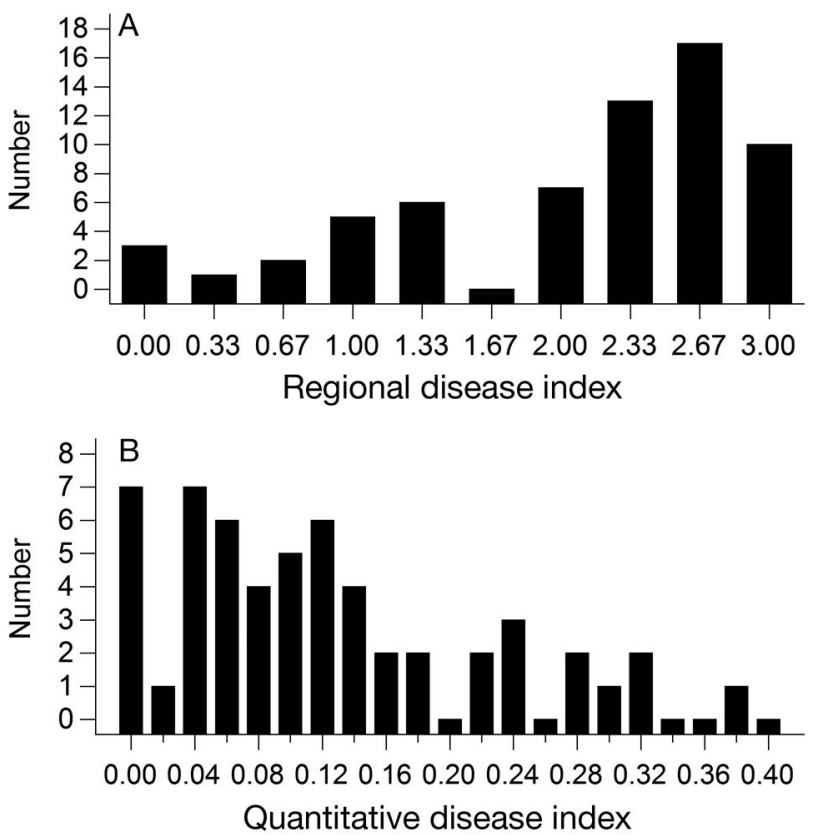

Fig. 2. Homarus americanus. Frequency distribution of maximum (A) regional disease index and (B) quantitative disease index values recorded for 55 lobsters during the study 
Table 1. Homarus americanus. Number of lobsters that died as a result of disease, heat stress, or unknown conditions, and percentage of total. CI: $95 \%$ confidence interval

\begin{tabular}{|lccc|}
\hline Cause & No. & Percent total (\%) & CI \\
\hline Disease & 13 & 23.6 & 11.6 \\
Heat & 9 & 16.4 & 10.1 \\
Unknown & 8 & 14.5 & 9.6 \\
Total & 30 & 54.5 & \\
\hline
\end{tabular}

following molting. One female lobster with fertilized eggs died while molting out of season (December). Lobsters with advanced disease could not extract themselves from their shells because the open lesions penetrated into the epidermis or new procuticle and the new shell could not separate from the old shell. One completed ecdysis, but did not form new calcified epicuticle on the uropods, which had been severely compromised by disease, and died within 6 wk. Of those that molted successfully, most were free of visible disease lesions after molting, but many exhibited exoskeletal defects in the form of abnormal coloration or shape at locations where severe lesions had existed prior to molting. Others had deformed appendages that severely hampered walking or feeding. Eight deaths $(14.5 \%)$ were unexplained. Excluding those deaths linked to high temperatures, mortality was strongly associated with high maximum values of QDI $(\geq 0.16)$; the $\chi^{2}$ value was 7.624 , with $p=0.006$ (Table 2 ). This level of the QDI index is more-or-less equal to an RDI index of 2.5, which would occur if 2 or more of the 3 body regions were scored as 3 (>50\% coverage). Lobsters with high QDI values were 7.0 times more likely to die than those with low values.

\section{Molting and growth}

Regression of QDI index values that were recorded in November 2007 (i.e. within 6 wk after capture for all lobsters) on CL indicated no significant relationship

Table 2. Homarus americanus. Contingency table analysis of lobster mortality versus the maximum quantitative disease index (QDI) value recorded during the present study. Nine lobsters that died during high temperatures in July 2008 were excluded. The $\chi^{2}$ value was 7.624, with $p=0.006$

\begin{tabular}{|lccc|}
\hline QDI & Survived & Died & Total \\
\hline$<0.16$ & 21 & 11 & 32 \\
$\geq 0.16$ & 3 & 11 & 14 \\
Total & 24 & 22 & 46 \\
\hline
\end{tabular}

between CL and disease severity for either male ( $\mathrm{n}=$ $\left.33, r^{2}=0.04\right)$ or female $\left(n=22, r^{2}=0.0013\right)$ lobsters (data not shown). Lobsters that molted successfully later in the year showed no significant relationship between CL and disease severity measured just before molting (sexes combined) ( $\mathrm{n}=33, \mathrm{r}^{2}=0.051$ ) (Fig. 3 ). During the first year of study, 33 lobsters successfully molted once and 7 molted twice. First molts occurred more-or-less continuously from February through July 2008, with a peak (7 molts) in May (Fig. 4). Among those that molted once, the average MI was $5.0 \pm$ $2.0 \mathrm{~mm}$ (mean $\pm \mathrm{SD}$ ), and PG was $7.8 \pm 3.0 \%$. Regression on pre-molt CL and QDI was highly significant for

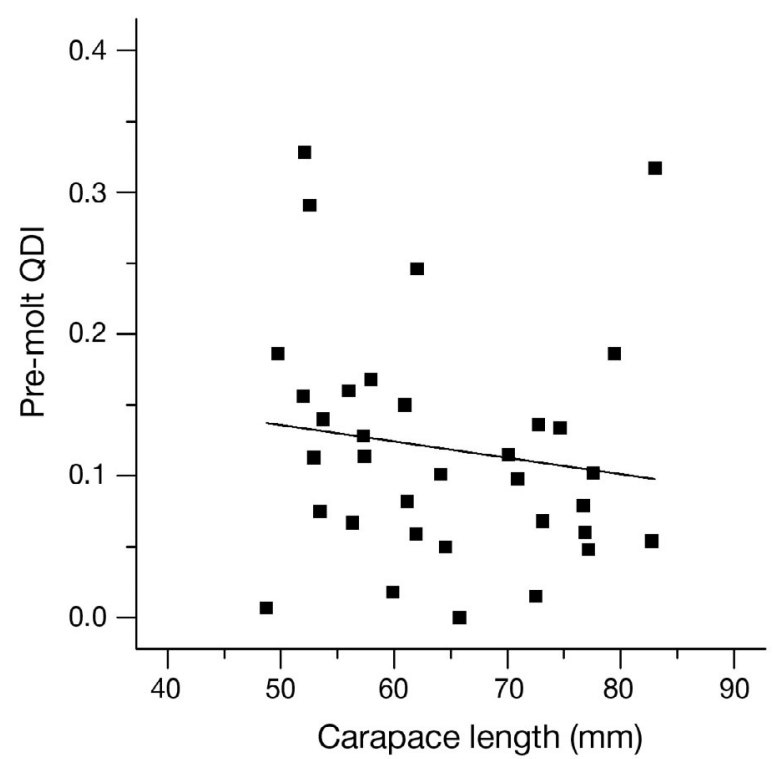

Fig. 3. Homarus americanus. Quantitative disease index (QDI) measured $<30 \mathrm{~d}$ before molting versus pre-molt carapace length (sexes combined). The correlation $\left(r^{2}=0.0211\right)$ is not significant

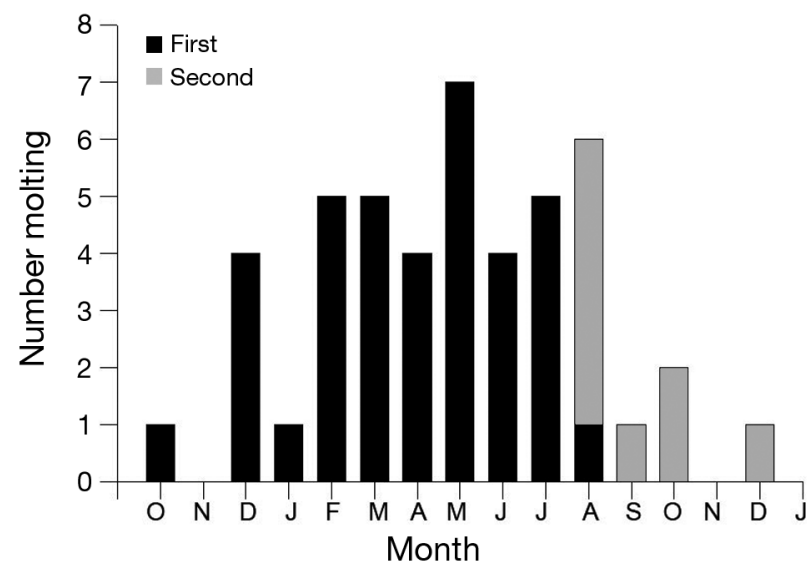

Fig. 4. Homarus americanus. Number of lobsters molting during each month of the laboratory study. Black bars are first molts; gray bars are second molts 
Table 3. Homarus americanus. Results of multiple regression analysis for lobster molt increment and proportional growth on pre-molt carapace length and pre-molt quantitative disease index

\begin{tabular}{|lllcccc|}
\hline Variable & Effect & SS & df & MS & F & p \\
\hline Molt increment & Regression & 41.69 & 2 & 20.85 & 6.829 & $<0.01$ \\
& Residual & 91.57 & 30 & 3.05 & & \\
Proportional growth & Regression & 0.005 & 2 & 0.003 & 3.331 & $<0.01$ \\
& Residual & 0.023 & 30 & 0.001 & & \\
\hline
\end{tabular}

both MI $\left(\mathrm{r}^{2}=0.313, F=6.829, \mathrm{p}<0.01\right)$ and PG $\left(\mathrm{r}^{2}=\right.$ $0.182, F=3.331, \mathrm{p}<0.05$ ) (Table 3). The regression equation for MI indicated a significant effect of both pre-molt CL $(t=2.407, \mathrm{p}<0.05)$ and QDI $(t=-2.439$, $\mathrm{p}<0.05$ ), but not for the intercept, whereas, the regression for PG indicated a significant effect of the intercept $(t=2.685, \mathrm{p}<0.02)$ and QDI $(t=-2.514, \mathrm{p}<0.02)$, but not of pre-molt CL (Table 4). All second molts occurred after 24 August 2008, with 5 occurring during the last week in August.

The stepwise regression of molting date on CL and disease severity (as QDI) showed that the latter had no significant effect, so it was removed from the regression. In contrast, CL had a significant effect on date of molting (Fig. 5); small lobsters (<70 mm) molted throughout the experiment, but larger lobsters molted after $90 \mathrm{~d}$, and most molted >180 d after the start of the experiment (15 October 2007). The regression of molting date on a single variable (CL) had a correlation of $0.545\left(r^{2}=0.292\right)$ and was highly significant $(n=34$, $\mathrm{p}<0.001)$.

\section{Temperature effects}

Temporal trends in the mean values for RDI and QDI in pre-molt lobsters were not detectable, because of the large amount of variance in any month (Fig. 6). However, monthly changes in the RDI or QDI values for individual non-molting lobsters (expressed as mean RDiff or QDiff) were detectable (Fig. 7). Initial data

Table 4. Homarus americanus. Coefficients of regression (Coeff.) of lobster molt increment and proportional growth on pre-molt carapace length (CL) and pre-molt quantitative disease index (QDI). NS: not significant

\begin{tabular}{|lcrrc|}
\hline Variable & Effect & Coeff. & $t$-value & $\mathrm{p}$ \\
\hline Molt increment & Constant & 1.426 & 0.687 & $\mathrm{NS}$ \\
& Pre-molt CL & 0.073 & 2.407 & $<0.05$ \\
& QDI & -9.076 & -2.439 & $<0.05$ \\
Proportional growth & Constant & 0.089 & 2.685 & $<0.02$ \\
& Pre-molt CL & 0.000 & 0.228 & NS \\
& QDI & -0.149 & -2.514 & $<0.02$ \\
\hline
\end{tabular}

showed a decline in disease progress (i.e. rate of change in lesion areas) as temperatures dropped from October through December 2007. However, there was little change in RDiff or QDiff after January 2008, even as water temperatures increased. The variance in the data declined continuously as fewer non-molted lobsters remained in the study and only 4 had not molted by May. By 7 July, all lobsters except one had either molted or died.

A large proportion of lobster mortalities occurred during the warmest period of water temperatures, prompting a closer look at those data. Mortalities occurred over a wide range of temperatures (Fig. 8A), but the proportion of mortalities occurring above $22^{\circ} \mathrm{C}$ was high relative to the number of days lobsters were held at those temperatures. The risk of death at each temperature can be estimated as the ratio of (mortalities)/(days held); the risk of death was $<15 \%$ for most of the year, but was $33 \%$ within a range of temperatures from 22 to $24^{\circ} \mathrm{C}$, and $67 \%$ at temperatures $>24^{\circ} \mathrm{C}$ (Fig. 8B).

The present study demonstrates unequivocally that epizootic shell disease has both lethal and sublethal impacts on the health of lobster Homarus americanus. Two indices of disease severity were developed that were usable for statistical analysis of data. The RDI is a better method for field biologists to use than the SDI because it provides data on location of lesions, is just as easy to use, and provides a resolution of 10 bins, as opposed to only 4 for the standard index. The QDI provides even greater resolution of the kind that is required for research using disease level as a response variable, although it is not applicable in the field. The QDI has a theoretical range from 0.000 to 1.000 , although the highest value observed in the present study was 0.381 . The reason for this is that only the dorso-lateral portions of the abdomen, carapace, and 


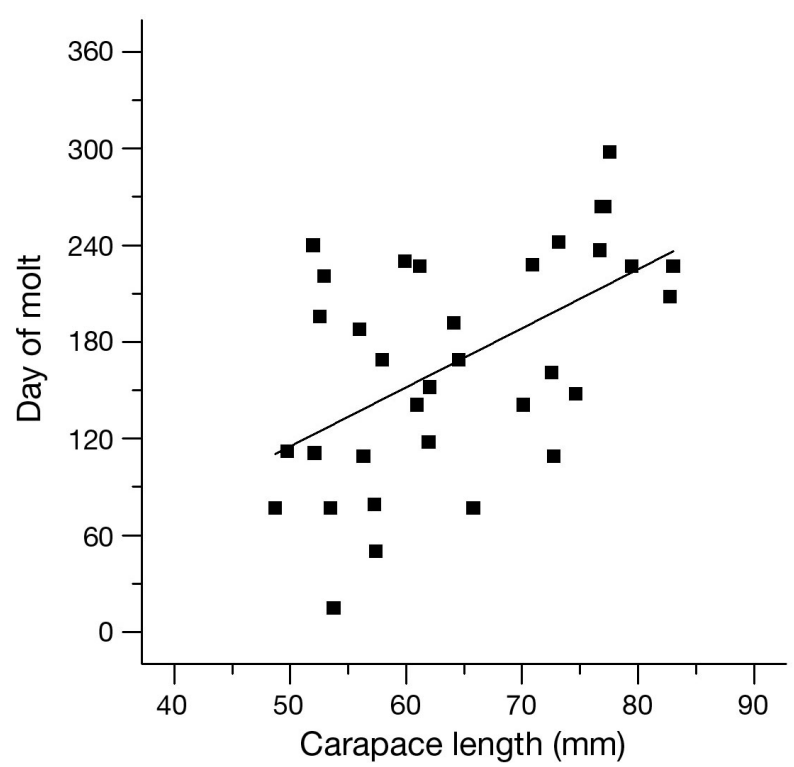

Fig. 5. Homarus americanus. Day of molt (days after 15 October 2007) versus lobster carapace length ( $\mathrm{mm})$. The correlation $\left(\mathrm{r}=0.545, \mathrm{r}^{2}=0.292\right)$ is significant $(\mathrm{n}=34, \mathrm{p}<0.001)$

chelae were scored; other appendages and the ventral sides were not traced.

The present study demonstrated that ESD causes significant mortality of lobsters. A minimum of $23.6 \pm$ $11.6 \%$ of lobsters died as a direct result of disease lesions, most often while molting. Other mortalities occurred during a period of high temperature, but, if only half of those lobsters died due to the additional stress of disease, the total disease-related mortality would be $28 \%$. In addition, there was a significant association between mortality and QDI values $>0.16$. There was also a significant sublethal effect, manifest as a negative correlation between disease severity (as QDI) and growth increment. This could imply either that diseased lobsters have lower growth rates due to the stress of disease, or that slowly growing lobsters are more susceptible to disease. The latter interpretation seems less likely, because in our sample of mostly juvenile lobsters there was no relationship between size and disease severity. Similarly, a relationship between lobster size and disease incidence was found lacking by other authors as well (Castro et al. 2005, Glenn \& Pugh 2005). Furthermore, Tlusty et al. (2007) have suggested that rapid growth, possibly due to increased temperature, may lead to ESD via the reduced density of cuticle layers. Many lobsters that molted successfully suffered from deformities in the exoskeleton and appendages that may have further impacts at a later time.

Because the present study was conducted in a confined laboratory setting, molting, mortality, and growth
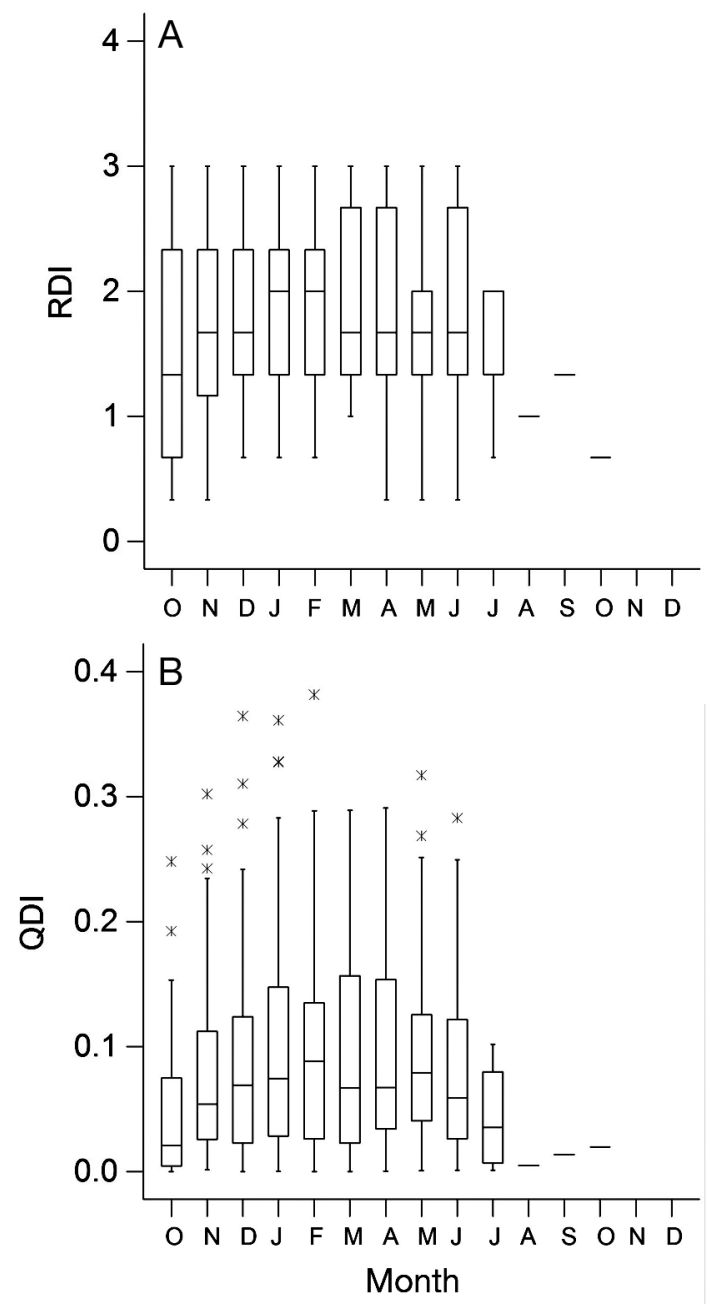

Fig. 6. Homarus americanus. Monthly values of (A) regional disease index (RDI) or (B) quantitative disease index (QDI) for pre-molt lobsters. Box encloses central $50 \%$ of data; horizontal line is median; vertical bars delimit observations within 1.5 box lengths of the 25th/75th percentile; asterisks represent data $>1.5$ box lengths from the 25th/75th percentile. Only 1 lobster remained unmolted after September 2008

may not have been the same as under natural conditions. However, we have kept lobsters alive for $>2 \mathrm{yr}$ and through multiple molts, suggesting that there is nothing inherently unhealthy about the holding conditions. Seawater flows through the SMAST laboratory rapidly, and its temperature does not differ significantly from that of nearby ocean water. Lobsters would not naturally feed on squid, but it is similar in composition to other molluscs. Herring is also not a natural food, but constitutes a large part of the diet of wild lobsters due to feeding in traps (Grabowski 2005). In a year-long laboratory study, juvenile lobsters fed a diet of $100 \%$ herring had a greater incidence of disease (measured as number of lesions) and mortality than those with less herring in the diet (Tlusty et al. 2008), 

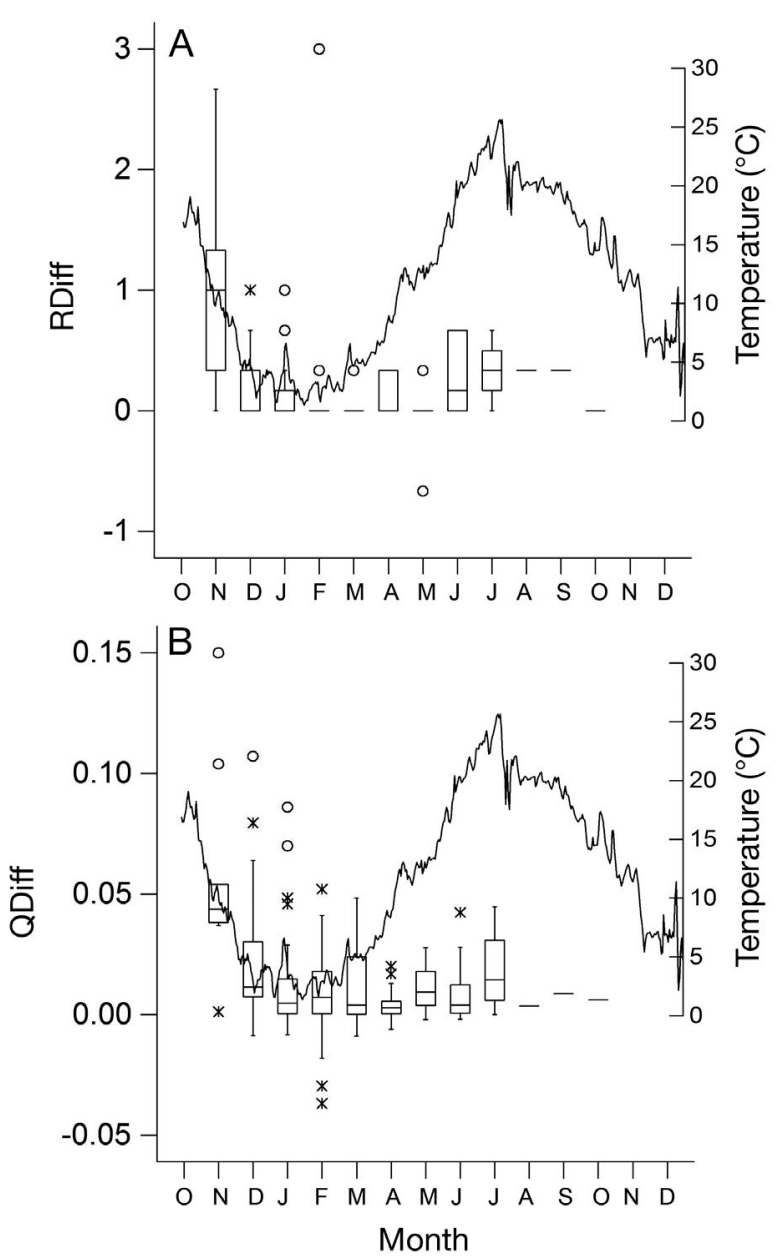

Fig. 7. Homarus americanus. Monthly mean values of (A) RDiff or (B) QDiff (changes in regional disease index or quantitative disease index, respectively) for pre-molt lobsters. Solid line is daily mean water temperature. Boxes as in Fig. 6; circles represent data $>3$ box lengths from the 25th/75th percentile

but our diet contained $<20 \%$ herring. The shell area affected by disease did not increase significantly on any lobster held in captivity. In fact, disease progress slowed to a halt in winter and did not increase much in the spring as water temperature rose. Instead, many lobsters molted out of their diseased shells.

Disease incidence has been reported to be greater among berried (egg-bearing) lobsters than among non-ovigerous females or males (Estrella 1991, Theriault et al. 2008). Estrella (1991) also concluded that disease incidence was significantly correlated with lobster size; the incidence of pitting and ulcers was greater in lobsters $>100 \mathrm{~mm}$ CL than in smaller ones. Both of these conclusions would follow if large and ovigerous lobsters molt less often and the incidence or severity of disease is a function of time since molting. However, the highest QDI values in the present study
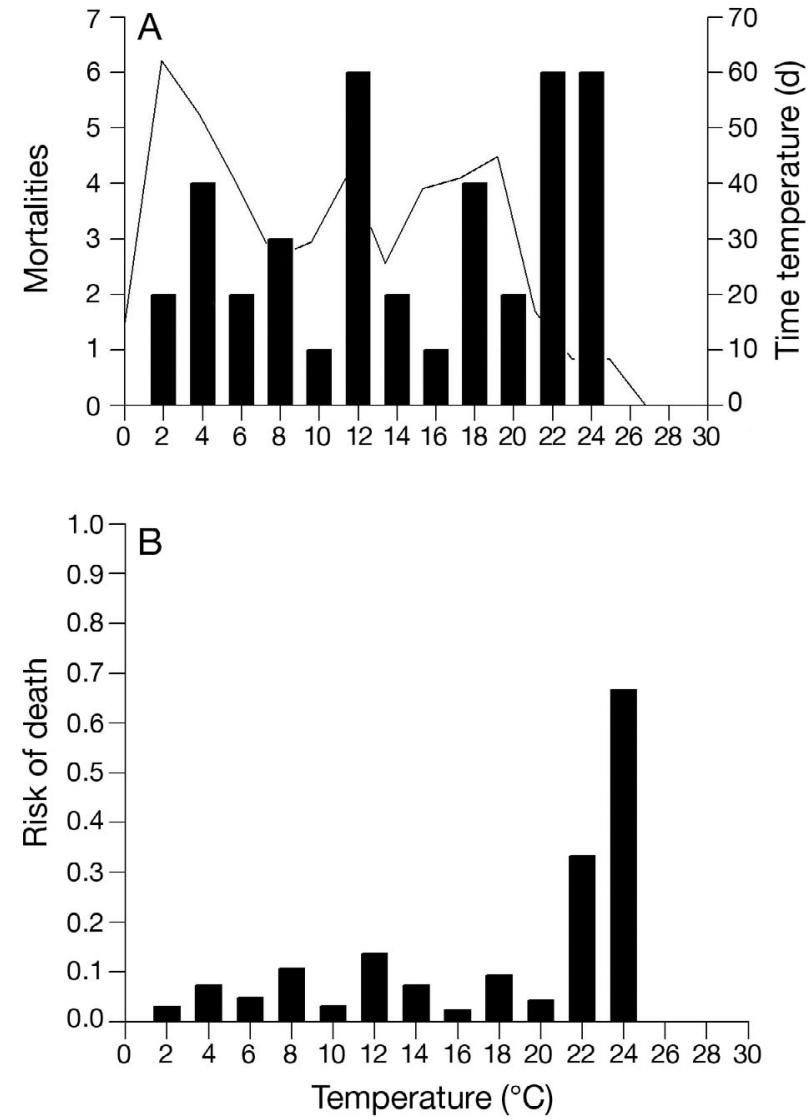

Fig. 8. Homarus americanus. (A) Number of lobsters that died (vertical bars, left axis) versus number of days held in each 2-degree temperature range (line, right axis). (B) Risk of death in each 2-degree temperature range, calculated as (mortalities)/(days held)

were exhibited by some of the smallest lobsters. Lobsters $<60 \mathrm{~mm}$ probably molted at least twice, possibly 3 times in 2007, and would have had shorter intermolt periods than larger lobsters. Those lobsters also molted earlier in the present study and would have had longer intervals over which to develop disease symptoms, but few had shown any symptoms as of March 2009 (1 yr after molting). Rinsing lobsters with seawater at monthly intervals apparently had no disease-quenching effects and could even have had a slightly exacerbating effect on disease development (Theriault et al. 2008). Estrella (1991) also reported that disease incidence was significantly correlated with shell hardness, but did not describe how hardness was determined and may have only grouped lobsters into subjective soft (i.e. recent post-molt) and hard (intermolt) categories. In contrast, Theriault et al. (2008) measured hardness with a durometer and demonstrated that incidence of shell disease was greater among soft-shelled (<90 durometer units, DU) intermolt lobsters than 
among hard shelled [>90 DU] pre-molt lobsters). Theriault et al. (2008) also demonstrated that lobsters with low levels of hemolymph total protein (TP, $<40 \mathrm{mg}$ $\mathrm{ml}^{-1}$ ) had a significantly greater incidence of shell disease and concluded that low TP was a strong predictor of shell disease, increasing the odds of developing disease by factors ranging from 4.3 to 26.8 .

Shell disease has been shown to have significant impacts on recruitment of a lobster population in Rhode Island (Wahle et al. 2009); settlement indices were a significant predictor of pre-recruit abundance from 1990 to 1996 , but the model became non-significant after the onset of shell disease in 1997. Inclusion of a term in the model reflecting the incidence of shell disease provided a significant fit to the data from 1990 to 2003 (Wahle et al. 2009). The present study suggests that direct mortality during molting is the most likely cause of this effect, and reduced growth rates may also play a role by increasing the time during which lobsters are small and more vulnerable to predation. The significant relationship between high QDI values and lobster mortality suggests that lobsters with severe disease symptoms are unlikely to survive another molt or contribute to population reproduction unless already carrying eyed embryos. While these findings may have significant applications for management purposes, they should be verified via large-scale tagging studies on wild lobsters before generalizing them to the southern New England lobster stock.

Acknowledgements. I sincerely thank S. O'Connor for her help in maintaining and feeding the lobsters held during this project. Partial salary support for B.G.S. was provided by NOAA awards NA05NMF4721132, NA06NMF4720096, and NA08NMF4720553. The views expressed herein are those of the author and do not necessarily reflect the views of NOAA or any other agencies.

\section{LITERATURE CITED}

Castro KM, Angell TE (2000) Prevalence and progression of shell disease in American lobster, Homarus americanus, from Rhode Island waters and the offshore canyons. J Shellfish Res 19:691-700

Castro K, Angell T, Somers B (2005) Lobster shell disease in southern New England: monitoring and research. In: Tlusty M, Halvorsen H, Smolowitz R, Sharma U (eds) Lobster shell disease workshop, University of Massachusetts, Boston, MA, Mar 12-13, 2005. New England Aquarium, Boston, MA, p 165-172

Chistoserdov AY, Smolowitz R, Mirasol F, Hsu A (2005a) Culture-dependent characterization of the microbial community associated with epizootic shell disease lesions in American lobster, Homarus americanus. J Shellfish Res 24:741-747

Chistoserdov AY, Gubbala SL, Smolowitz R, Mirasol F, Hsu A (2005b) A microbiological assessment of epizootic shell disease in American lobster indicates its strictly dermal etiology. In: Tlusty M, Halvorsen H, Smolowitz R, Sharma
U (eds) Lobster shell disease workshop, University of Massachusetts, Boston, MA, Mar 12-13, 2005. New England Aquarium, Boston, MA, p 12-20

Cobb JS, Castro KM (2006) Shell disease in lobsters: a synthesis. University of Rhode Island, Kingston, RI

Estrella BT (1991) Shell disease in American lobster (Homarus americanus, H. Milne Edwards, 1837) from Massachusetts coastal waters with considerations for standardizing sampling. J Shellfish Res 10:483-488

Gibson M, Wahle RA (2005) Reduced recruitment of inshore lobster in Rhode Island in association with an outbreak of shell disease and management implications. In: Tlusty $M$, Halvorsen H, Smolowitz R, Sharma U (eds) Lobster shell disease workshop, University of Massachusetts, Boston, MA, Mar 12-13, 2005. New England Aquarium, Boston, MA, p 115-130

Glenn RP, Pugh TL (2005) Observations on the chronology and distribution of lobster shell disease in Massachusetts coastal waters. In: Tlusty M, Halvorsen H, Smolowitz R, Sharma U (eds) Lobster shell disease workshop, University of Massachusetts, Boston, MA, Mar 12-13, 2005. New England Aquarium, Boston, MA, p 141-155

Glenn RP, Pugh TL (2006) Epizootic shell disease in America lobster (Homarus americanus) in Massachusetts coastal waters: interactions of temperature, maturity, and intermolt duration. J Crustac Biol 26:639-645

Grabowski JH (2005) Are we using herring to farm lobsters? The effect of herring bait on lobster growth, and the fate of discarded bait on bottom habitat. Gulf of Maine Research Institute, Portland, ME

Howell P (2005) Status of shell disease in Long Island Sound. In: Tlusty M, Halvorsen H, Smolowitz R, Sharma U (eds) Lobster shell disease workshop, University of Massachusetts, Boston, MA, Mar 12-13, 2005. New England Aquarium, Boston, MA, p 106-114

> Kapareiko D, Robohm RA, Ziskowski J, Sennefelder GR (2003) Surface area and allometric growth relationships among major body parts of the American lobster, Homarus americanus. Crustaceana 76:769-780

Laufer H, Demir N, Pan X (2005) Shell disease in the American lobster and its possible relations to alkylphenols. In: Tlusty M, Halvorsen H, Smolowitz R, Sharma U (eds) Lobster shell disease workshop, University of Massachusetts, Boston, MA, Mar 12-13, 2005. New England Aquarium, Boston, MA, p 72-75

McKown K, Burgess R, Nunnenkamp P (2005) Incidence of lobster shell disease in American lobster (Homarus americanus) in New York waters. In: Tlusty M, Halvorsen $\mathrm{H}$, Smolowitz R, Sharma U (eds) Lobster shell disease workshop, University of Massachusetts, Boston, MA, Mar 12-13, 2005. New England Aquarium, Boston, MA, p 173-176

O'Kelly CJ (2005) The lobster back biofilm: possible role of the total microbial community in lobster shell disease. In: Tlusty M, Halvorsen H, Smolowitz R, Sharma U (eds) Lobster shell disease workshop, University of Massachusetts, Boston, MA, Mar 12-13, 2005. New England Aquarium, Boston, MA, p 22-24

Prince DL, Bayer RC (2005) Are all lobsters created equal? Understanding the role of host susceptibility in the development of shell disease in Homarus americanus. In: Tlusty M, Halvorsen H, Smolowitz R, Sharma U (eds) Lobster shell disease workshop, University of Massachusetts, Boston, MA, Mar 12-13, 2005. New England Aquarium, Boston, MA, p 58-67

Sindermann CJ (1989) Principal diseases of marine fish and shellfish, Vol 2. Academic Press, San Diego, CA 
Smolowitz R, Chistoserdov AY, Hsu A (2005a) A description of the pathology of epizootic shell disease in the American lobster, Homarus americanus, H. Milne Edwards, 1837. J Shellfish Res 24:749-756

Smolowitz R, Chistoserdov AY, Hsu A (2005b) Epizootic shell disease in the American lobster, Homarus americanus. In: Tlusty M, Halvorsen H, Smolowitz R, Sharma U (eds) Lobster shell disease workshop, University of Massachusetts, Boston, MA, Mar 12-13, 2005. New England Aquarium, Boston, MA, p 2-11

Sullivan ER, Nelson KM (2005) A comparison of bacterial diversity and abundance on healthy and shell diseased American lobsters. In: Tlusty M, Halvorsen H, Smolowitz $\mathrm{R}$, Sharma U (eds) Lobster shell disease workshop, University of Massachusetts, Boston, MA, Mar 12-13, 2005. New England Aquarium, Boston, MA, p 45-47

Tarsitano SF, Lavalli KL (2005) Shell disease in the American lobster Homarus americanus: Disease or malfunction of the calcification process followed by opportunistic infection? In: Tlusty M, Halvorsen H, Smolowitz R, Sharma U (eds) Lobster shell disease workshop, University of Massa-

Editorial responsibility: Ken Hasson, College Station, Texas, USA chusetts, Boston, MA, Mar 12-13, 2005. New England Aquarium, Boston, MA, p 83-85

Theriault M, VanLeeuwen J, Morrison M, Cawthorn R (2008) Risk factors for the development of shell disease in impounded populations of the American lobster, Homarus americanus. J Shellfish Res 27:1239-1245

Tlusty MF, Smolowitz RM, Halvorsen HO, DeVito SE (2007) Host susceptibility hypothesis for shell disease in American lobsters. J Aquat Anim Health 19:215-225

Tlusty MF, Myers A, Metzler A (2008) Short- and long-term dietary effects on disease and mortality in American lobster Homarus americanus. Dis Aquat Org 78:249-253

Wahle RA, Gibson M, Fogarty M (2009) Distinguishing disease impacts from larval supply effects in a lobster fishery collapse. Mar Ecol Prog Ser 376:185-192

Wilson C (2005) Observations of shell disease in coastal Maine waters: 2003 and 2004. In: Tlusty M, Halvorsen $H_{\text {, }}$ Smolowitz R, Sharma U (eds) Lobster shell disease workshop, University of Massachusetts, Boston, MA, Mar 12-13, 2005. New England Aquarium, Boston, MA, p 156-159

Submitted: June 2, 2009; Accepted: August 25, 2009 Proofs received from author(s): December 14, 2009 